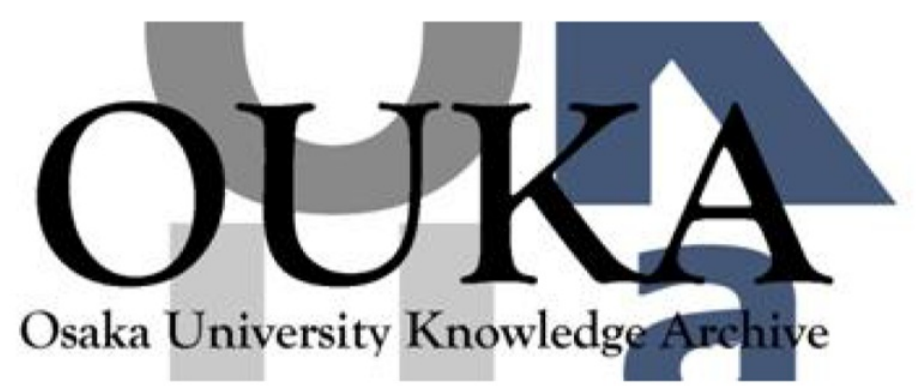

\begin{tabular}{|c|l|}
\hline Title & $\begin{array}{l}\text { Studies of Raman scattering in novel } \\
\text { disubstituted acetylene polymers }\end{array}$ \\
\hline Author(s) & $\begin{array}{l}\text { Fujii, Akihiko; Shkunov, Maxim N. ; Vardeny, Z. } \\
\text { Valy et al. }\end{array}$ \\
\hline Citation & $\begin{array}{l}\text { Proceedings of SPIE - The International Society } \\
\text { for Optical Eng ineering. 3145 p.533-p.543 }\end{array}$ \\
\hline Issue Date & $1997-12-01$ \\
\hline oaire:version & VoR \\
\hline URL & https://hdl. handle. net/11094/76945 \\
\hline rights & \\
\hline Note & \\
\hline
\end{tabular}

Osaka University Knowledge Archive : OUKA

https://ir. Library. osaka-u. ac. jp/

Osaka University 


\title{
Studies of Raman scattering in novel disubstituted acetylene polymers
}

\author{
Akihiko Fujii ${ }^{a, b}$, Maxim N. Shkunov", Zeev V. Vardeny", Kazuya Tadab, Katsumi Yoshino ${ }^{b}$, \\ Masahiro Teraguchi ${ }^{\mathrm{c}}$, and Toshio Masuda ${ }^{\mathrm{c}}$ \\ 'Department of Physics, University of Utah, Salt Lake City, UT 84112, USA \\ bDepartment of Electronic Engineering, Faculty of Engineering, Osaka University, \\ 2-1 Yamada-oka, Suita, Osaka 565, Japan \\ 'Division of Polymer Chemistry, Faculty of Engineering, Kyoto University, Kyoto 606-01, Japan
}

\begin{abstract}
We have studied resonant and non-resonant Raman scattering spectra in thin films of novel disubstituted acetylene polymers such as poly(1-ethyl-2-phenylacetylene) (PEtPA), poly(1-n-hexyl-2-phenylacetylene) (PHxPA) and poly(1-phenyl-2-p-nbutylphenylacetylene) (PDPA-nBu), which possess high photoluminescence (PL) quantum efficiency. We found that the Raman scattering frequency dispersion is smaller in disubstituted acetylene polymers than in other acetylene polymers, in agreement with many other strongly luminescent polymers. Assuming the model of short polyene conjugation length in these acetylene polymers, we can obtain the conjugation length $(N)$ for each polymer from the respective phonon frequency of the carbon-carbon double bond; we obtained $\mathrm{N}=7$ for PDPA-nBu, and $\mathrm{N}=5$ or 6 for PHxPA and PEtPA. The related energies of $1^{1} B_{v}$ and $2^{1} A_{g}$ can be estimated from these $\mathrm{N}$ and are in good agreement with the respective absorption and PL spectra of the various disubstituted polymers.
\end{abstract}

Keywords: conducting polymers, disubstituted polyacetylenes, Raman Scattering, conjugation length, electronic structure 


\section{INTRODUCTION}

The use of $\pi$-conjugated conducting polymers as functional materials has attracted much attention from the point of view of basic science and applications, because of their high processability, stability, and promising electrical and optical properties. Trans- polyacetylene ( $t-\mathrm{PA})$, which was the first synthesized $\pi$-conjugated conducting polymer, was reported as a solid material with no photoluminescence (PL)'; this was explained by the soliton model. However, it was latter found that a weak PL can be still observed in the infrared spectral region, ${ }^{2}$ and therefore, the anomalous PL properties of $t$-PA are better interpreted by the relative position in energy of the excited $1^{1} B_{v}$ and $2^{1} A_{g}$ states in the $C_{2 b}$ group notation. Recently, we have synthesized novel alkyl and aromatic substituted PA and found that they have high PL quantum efficiency (QE) $\eta ; \eta \geq 85 \%$ for poly(1-n-hexyl-2-phenylacetylene) (PHxPA), and $\eta \geq 45 \%$ for poly(1-phenyl-2-p-n-butylphenylacetylene) (PDPA- $n \mathrm{Bu})$. It is, therefore important to investigate the most strongly resonantly coupled vibrational modes of these polymers in order to determine their electronic structures in relation with the explanation of their emission. In this paper, we present a study of the Raman scattering spectra in the novel disubstituted polyacetylenes and discuss the results in terms of the conjugation lengths distribution and electronic structures.

\section{EXPERIMENTAL}

Disubstituted acetylene polymers such as poly(1-ethyl-2-phenylacetylene) (PEtPA), PHxPA and PDPA-nBu as shown in Fig. 1 were studied in present work; the synthesis of these PA derivatives is described elsewhere. ${ }^{3,4}$ These derivatives are soluble in conventional solvents such as chloroform. ${ }^{5}$

Thin films were prepared on quartz substrates by a casting method utilizing the chloroform solution containing the PA. The typical film thickness was 1-3 $\mu \mathrm{m}$.

Raman scattering from the substituted PA films was obtained at $300 \mathrm{~K}$ in vacuum, in a backscattering geometry as shown in Fig. 2 using various excitation lasers, including ultraviolet and visible $\mathrm{Ar}^{+}, \mathrm{Ar}^{+}$-pumped $\mathrm{Rhodamine}^{6 \mathrm{G}}$ dye and $\mathrm{Ar}^{+}$-pumped Ti:sapphire lasers. The excitation photon energy used in this study was $1.65-3.41 \mathrm{eV}$. The excitation power was kept at 10-50 $\mathrm{mW}$ to avoid any photoinduced damages. Scattered light was focused onto the entrance slit of a triple spectrograph (Spex 1877) equipped with 300-, 600-, and 1200-grooves/mm ruled gratings. The Raman signal was detected using an optical multichannel detection system with a liquid nitrogen cooled CCD (Tektronics). The exposure times to record the signals were typically 1-20 seconds. 
<smiles>Cc1ccccc1CC(C)C(C)C</smiles><smiles>c1ccc2c(c1)CCCCC2</smiles>

PEtPA<smiles>CCCCc1ccc(C(C)=C(c2ccccc2)C(C)C)c(C(C)C)c1</smiles>

PDPA- $n B u$

Fig. 1 The molecular repeat units of disubstituted PA used in this work.

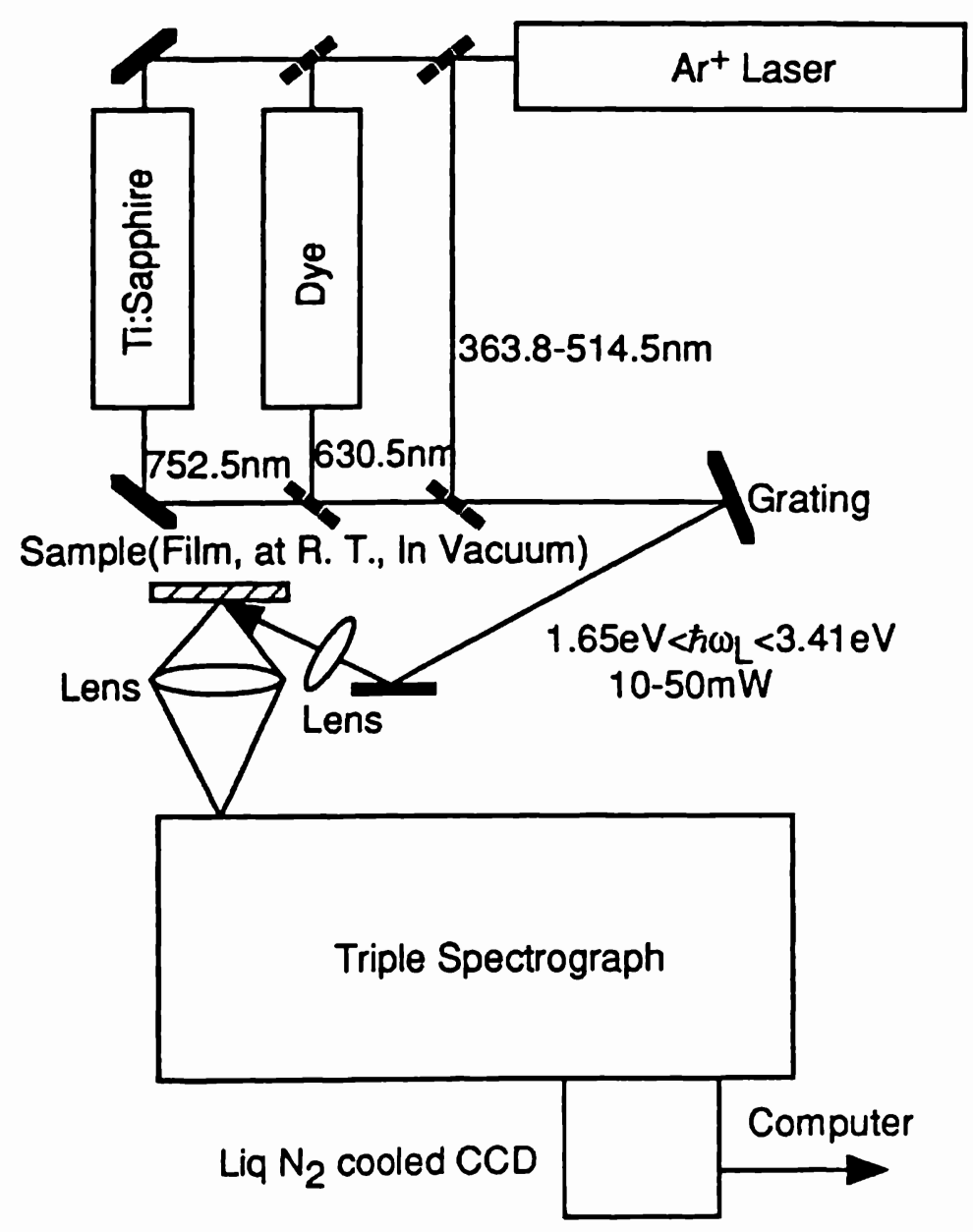

Fig. 2 The measurement system for Raman scattering spectroscopy. 


\section{RESULTS}

The PA derivatives used in this study possess high PL QE. From optical absorption measurements, we found that the energies at the absorption peak $\left(\alpha_{\max }\right)$ of PEtPA, PHxPA and PDPA-nBu were $3.60 \mathrm{eV}, 3.54 \mathrm{eV}$, and $2.95 \mathrm{eV}$, respectively. We note that all excitation $\hbar \omega_{L} \leq 3 \mathrm{eV}$ should be thus considered to be below resonance, whereas $\hbar \omega_{L} \geq 3.3 \mathrm{eV}$ are at resonance. When the PEtPA and PHxPA films were excited at $350 \mathrm{~nm}$, then the energies at the photoluminescence peaks $\left(\mathrm{PL}_{\max }\right)$ were measured to be $2.70 \mathrm{eV}$ and $2.67 \mathrm{eV}$, respectively. The emission color of PEtPA and PHxPA was thus visible blue. In the case of PDPA-nBu, when light at $400 \mathrm{~nm}$ was used, it was found that $\mathrm{PL}_{\operatorname{mex}}$ was $2.38 \mathrm{eV}$, which implies visible green emission. We note that all of these PA derivatives show large Stokes shifts as evident from the data shown in Fig. 3.

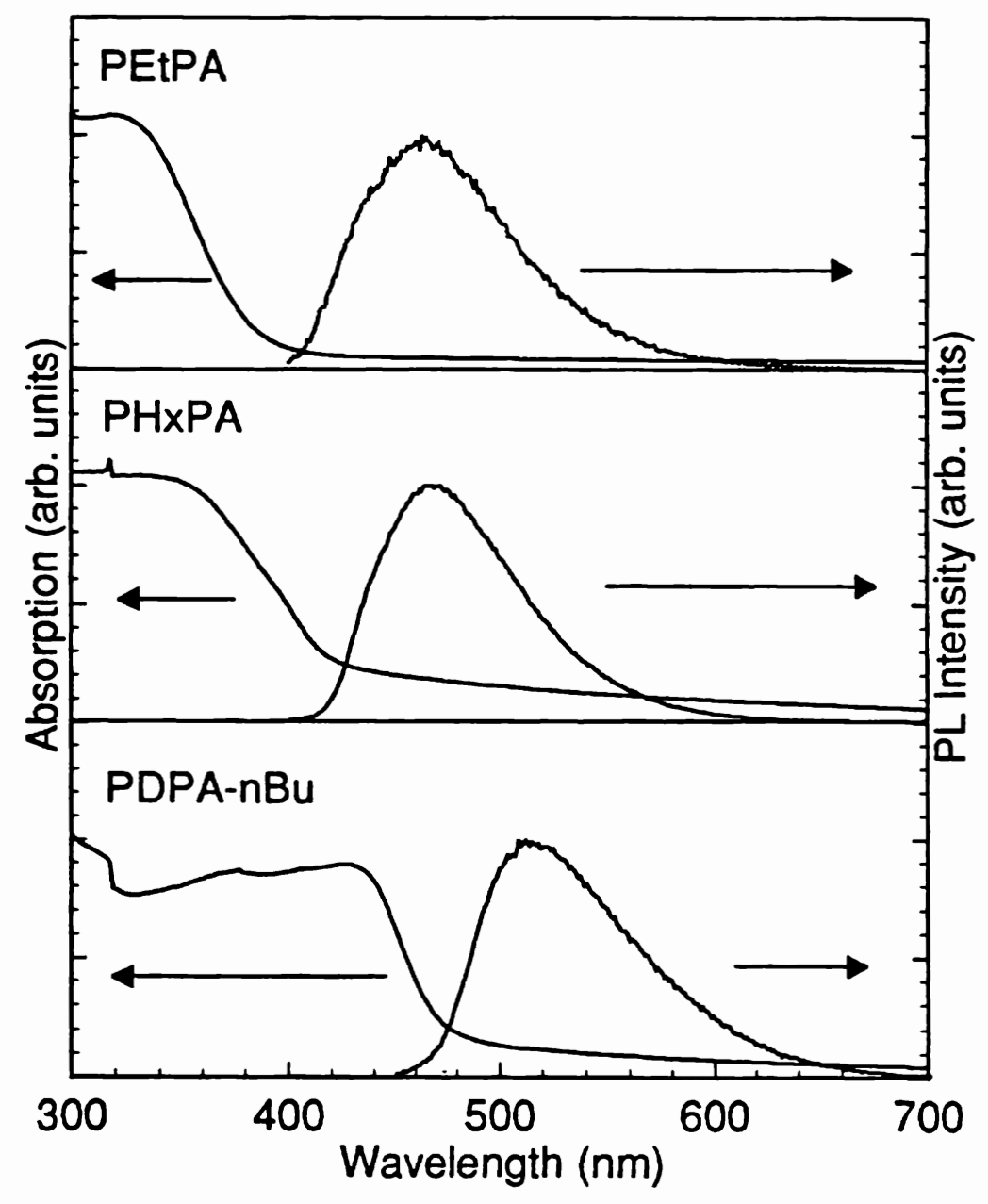

Fig. 3 The absorption and photoluminescence spectra of the disubstituted PA. 
Raman scattering spectra of PEtPA, PHxPA and PDPA-nBu are shown in Figs. 4(a), 5(a) and 6(a), respectively, for various laser excitation photon energies. The Raman frequencies of the strongest vibration in these spectra are found to be around $1595 \mathrm{~cm}^{-1}$ (PETPA), $1590 \mathrm{~cm}^{-1}$ (PHxPA) and $1560 \mathrm{~cm}^{-1}$ (PDPA-nBu). These strong Raman modes originate from the stretching vibration of the carbon-carbon double bonds $\left(v_{c_{-\infty}}\right)$. When PDPA-nBu was excited at $\hbar \omega_{L}=3.41 \mathrm{eV}$, the energy of which is larger than $\alpha_{\max }$, only the line at $1560 \mathrm{~cm}^{-1}$ was observed and thus is due to resonant Raman scattering. The resonant Raman scattering modes of PELPA and PHxPA could not be observed at present, because of the limitation of short wavelengths as excitation sources of our measurement system. Other Raman spectra are considered to be at off resonant condition.
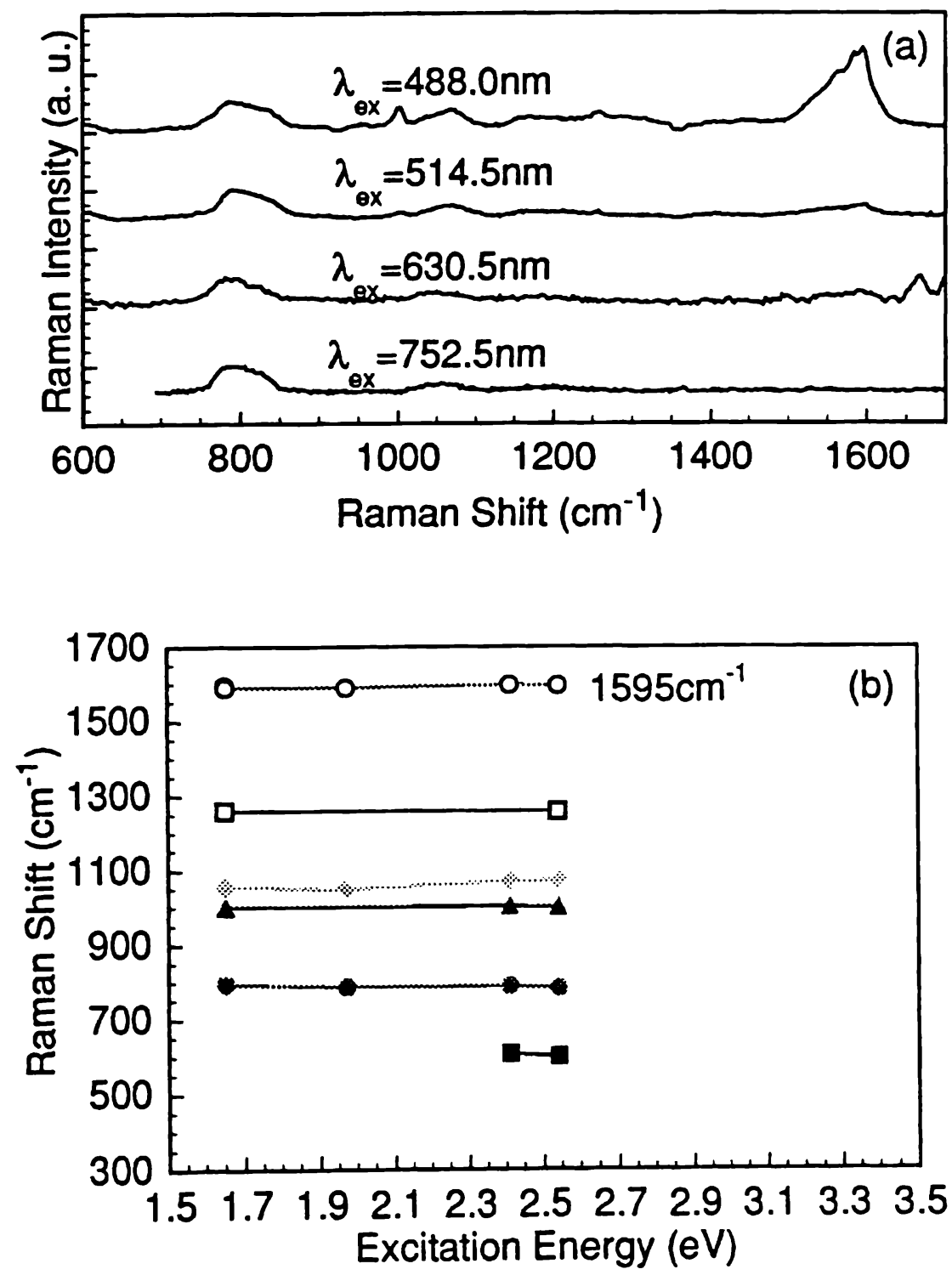

Fig. 4 Raman scattering spectra of PELPA (a) and the excitation energy dependence of the various Raman frequencies (b). 

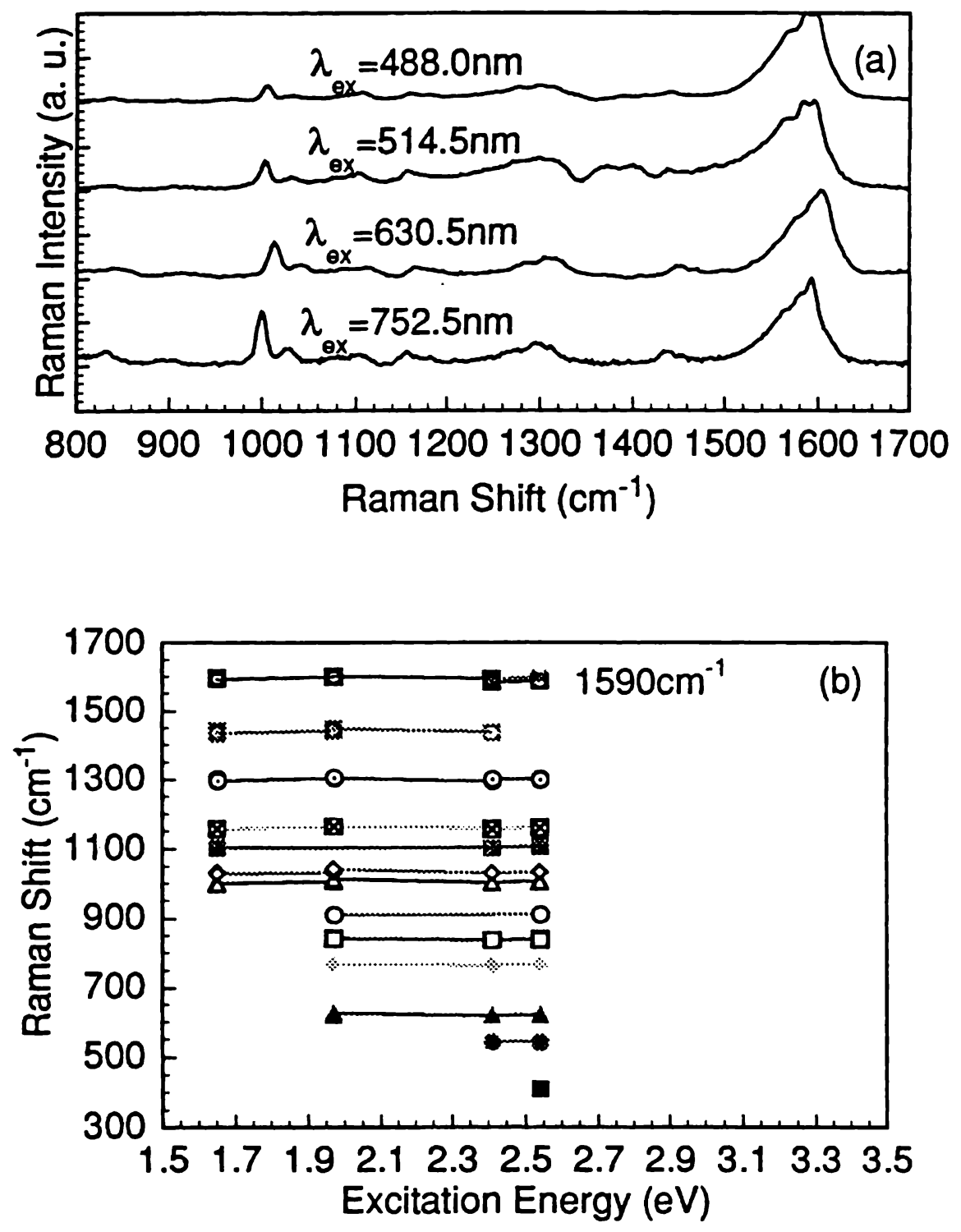

Fig. 5 Same as in Fig. 4 but for PHxPA. 

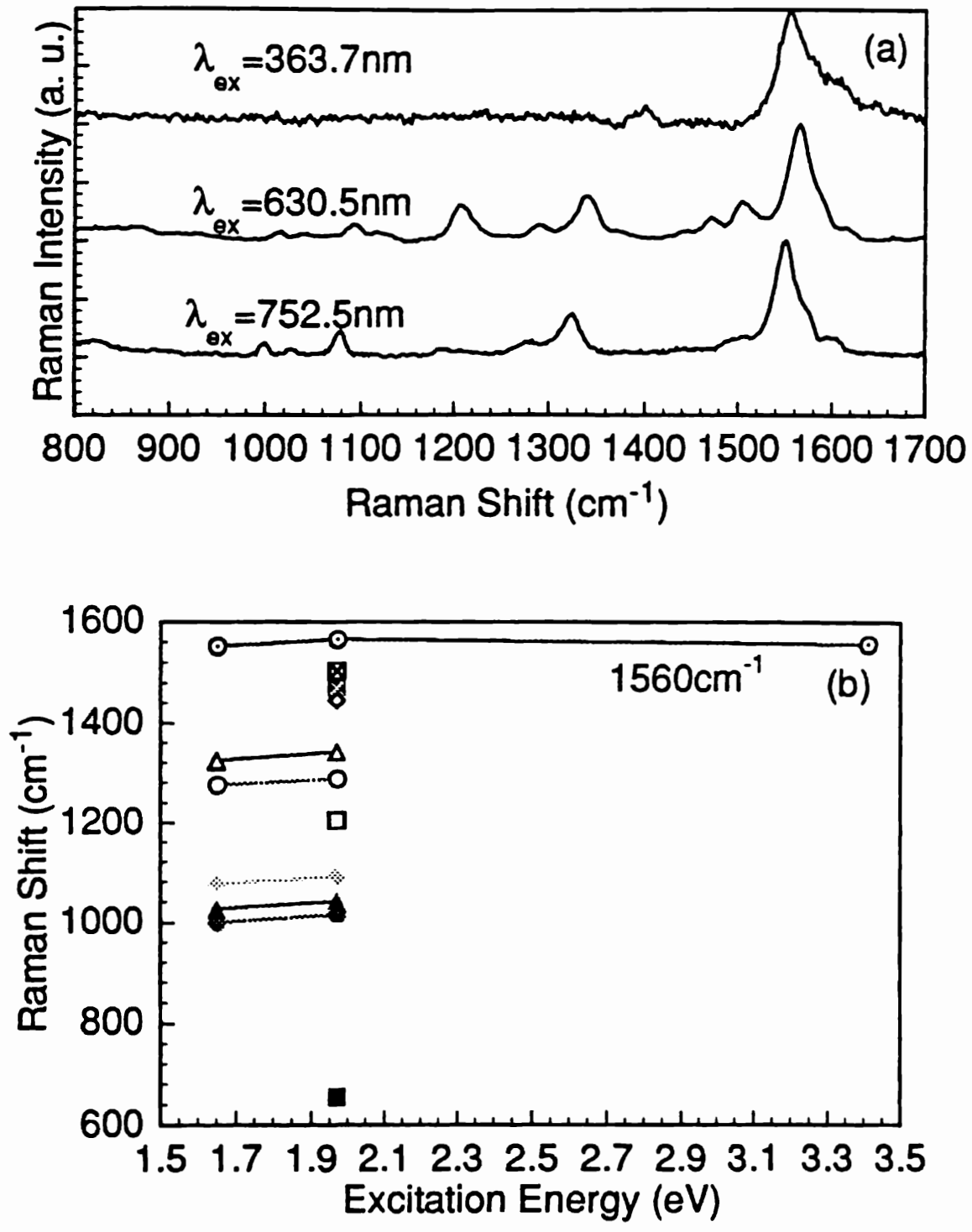

Fig. 6 Same as in Fig. 4 but for PDPA-nBu.

The variation of the observed Raman lines with $\hbar \omega_{L}$ is summarized in Figs. 4(b), 5(b) and 6(b), respectively. It is seen that as $\hbar \omega_{\mathrm{L}}$ increases from $1.65 \mathrm{eV}$ to $3.41 \mathrm{eV}$, there exists only a little upward shift of the Raman frequencies. These shifts are much smaller in disubstituted acetylene polymers than in mono-substituted polyacetylene derivatives such as poly $(0$ trimethylsilylphenylacetylene). ${ }^{6}$ It has already been clarified that luminescent $\pi$-conjugated polymers show only a weak Raman scattering dispersion, in comparison with non-luminescent $\pi$-conjugated polymers. ${ }^{7}$ In this respect, the disubstituted acetylene polymers, which possess high luminescent properties are in good agreement with the trend discovered before. 
In the case of polyenes, it has been widely reported that the frequency $v_{c a c}$ measured by Raman scattering blue shifts depending on the conjugation length, as shown in Fig. 7. Moreover, it has been found that $v_{c x}$ follows the expression

$$
v_{c \rightarrow c}=a+b / N \text {, }
$$

where $\mathrm{N}$ is the conjugation length (i.e. number of $\mathrm{C}=\mathrm{C}$ in the chain), and both $\mathrm{a}$ and $\mathrm{b}$ are constants found to be $\mathrm{a}=1438 \mathrm{~cm}^{-1}$, $\mathrm{b}=830 \mathrm{~cm}^{-1}$. $^{8}$ Similarly, the energies of the $1^{1} B_{u}$ and $2^{1} A_{g}$ states also follow the equations

$$
\begin{aligned}
& \mathrm{E}\left(1^{1} B_{\nu}\right)=\mathrm{A}+\mathrm{B} / \mathrm{N}, \\
& \mathrm{E}\left(2^{1} A_{\nu}\right)=A^{\prime}+\mathrm{B}^{\prime} / \mathrm{N},
\end{aligned}
$$

where $A, B, A^{\prime}$ and $B^{\prime}$ are constants found to be $A=14200 \mathrm{~cm}^{-1}, B=70600 \mathrm{~cm}^{-1}, A^{\prime}=7370 \mathrm{~cm}^{-1}$ and $B^{\prime}=85500 \mathrm{~cm}^{-1} .9$ These relations are shown in Fig. 8.

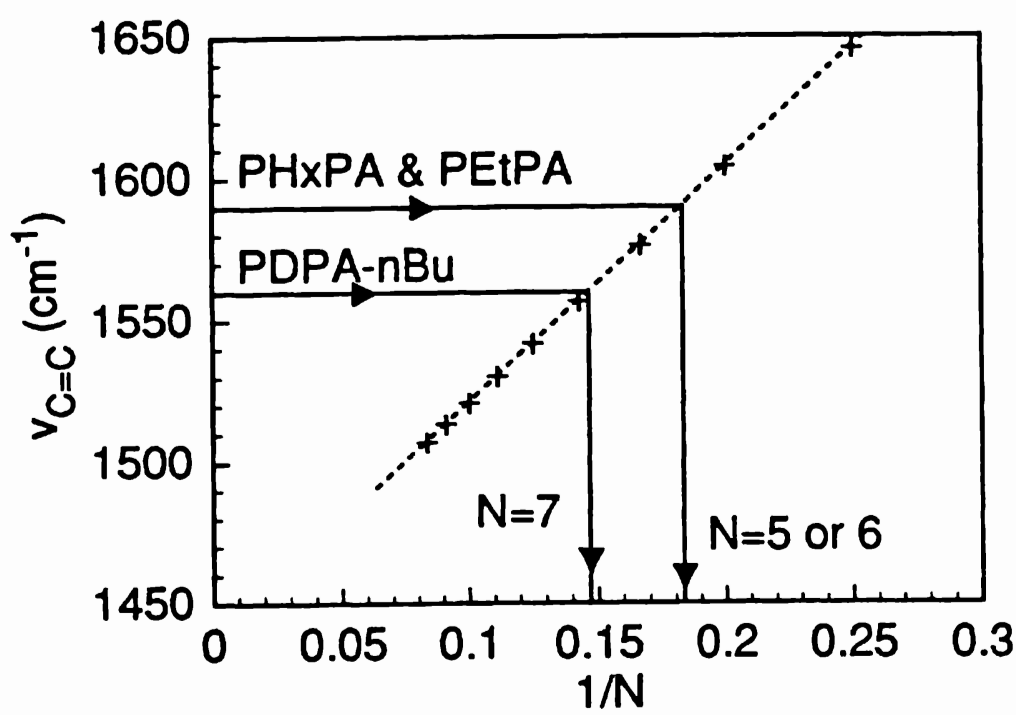

Fig. 7 Raman shift of $v_{c \infty c}$ as a function of inverse conjugation length measured in polyenes. [Ref. 8] $\mathrm{N}$ for the various disubstituted PA is found.

If we adopt the model of short conjugation length for the PA derivatives, we can obtain $\mathrm{N}$ for each polymer, from the respective $v_{c-c}$ measured by Raman scattering as shown in Fig. 7. Using this procedure, we found $N=7$ in PDPA-nBu, and $N=5$ or 6 in PHxPA and PEtPA, respectively. Using these conjugation lengths and the above relations (2) and (3), we estimated the energies of $1^{1} B_{v}$ and $2^{1} A_{g}$ as shown in Fig. 8. In the case of PDPA- $n \mathrm{Bu}$, we found $E\left(1^{1} B_{v}\right)=3.01 \mathrm{eV}$, $\mathrm{E}\left(2^{1} A_{\vartheta}\right)=2.43 \mathrm{eV}$. In the case of PHxPA and PEtPA, we found $\mathrm{E}\left(1^{1} B_{\downarrow}\right)=3.22-3.51 \mathrm{eV}, \mathrm{E}\left(2^{1} A_{g}\right)=2.68-3.03 \mathrm{eV}$. These energies are in good agreement with the respective $\alpha_{\max }$ and $\mathrm{PL}_{\operatorname{mex}}$ of the various PA derivatives, as shown in Table I. 


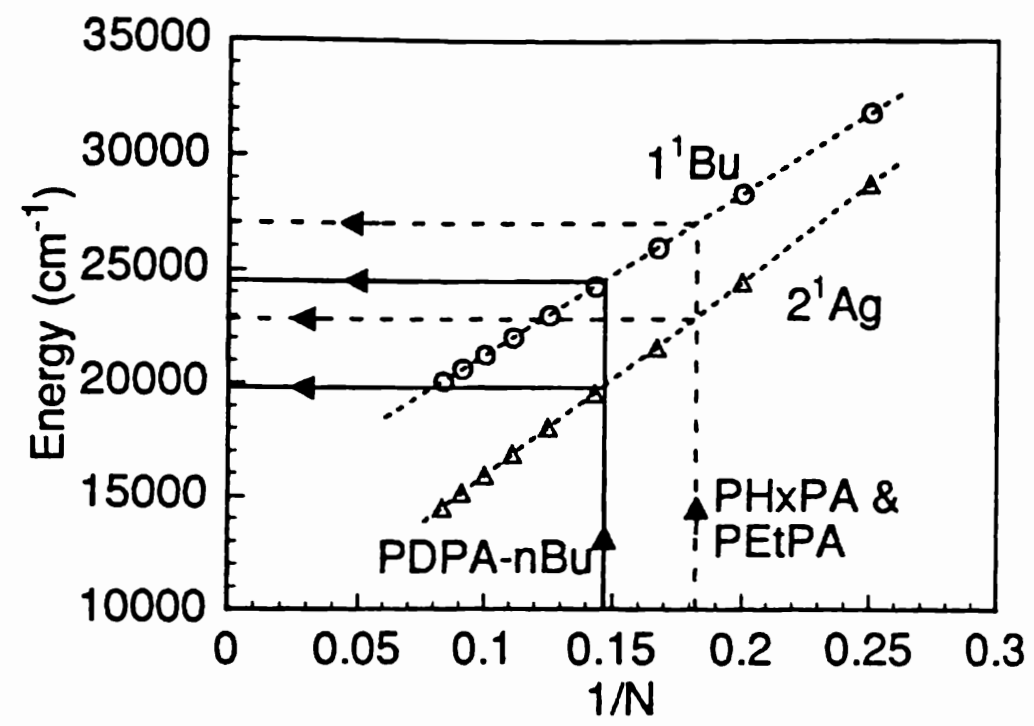

Fig. $81^{1} B_{v}$ and $2^{1} A_{g}$ energies vs inverse of conjugation length measured in polyenes. [Ref. 9] The respective $\mathrm{E}\left(1^{1} B_{\nu}\right)$ and $\mathrm{E}\left(2^{\mathrm{A}} A_{\rho}\right)$ for the PA derivatives are shown.

Table I. Raman frequencies of $C=C$ stretching, the estimate of the conjugation lengths and the energies of $1^{1} B_{v}$ and $2^{1} A_{q}$ in PA derivatives. $\alpha_{\max }$ and PL $\max _{\max }$ are the energies obtained from the spectral peaks of absorption and photoluminescence, respectively.

\begin{tabular}{cccccccc}
\hline \hline No. & Polymer & $\mathrm{v}_{\mathrm{C} \rightarrow \mathrm{C}}$ & $\mathrm{N}$ & $\mathrm{E}\left(1^{1} B_{u}\right)$ & $\alpha_{\max }$ & $\mathrm{E}\left(2^{1} A_{g}\right)$ & $\mathrm{PL}_{\max }$ \\
\hline 1 & PEtPA & $1595 \mathrm{~cm}^{-1}$ & 5 or 6 & $3.22-3.51 \mathrm{eV}$ & $3.60 \mathrm{eV}$ & $2.68-3.03 \mathrm{eV}$ & $2.70 \mathrm{eV}$ \\
2 & PHxPA & $1590 \mathrm{~cm}^{-1}$ & 5 or 6 & $3.22-3.51 \mathrm{eV}$ & $3.54 \mathrm{eV}$ & $2.68-3.03 \mathrm{eV}$ & $2.67 \mathrm{eV}$ \\
3 & PDPA- $n \mathrm{Bu} 1560 \mathrm{~cm}^{-1}$ & 7 & $3.01 \mathrm{eV}$ & $2.95 \mathrm{eV}$ & $2.43 \mathrm{eV}$ & $2.38 \mathrm{eV}$ \\
\hline \hline
\end{tabular}

\section{DISCUSSION}

The origin of the efficient PL emission of the PA derivatives cannot be definitively explained at this time, but some suggestions based on our results can be given. The excitation energy dependences of the various Raman frequencies in PA 
derivatives are quite similar to that in other luminescent conjugated polymers investigated before. ${ }^{7}$ This suggests that $1^{1} B_{v}$ may be located below the $2^{1} A_{g}$ in PA derivatives, in agreement with other luminescent conjugated polymers. Here, we use the $\mathrm{C}_{2 \mathrm{~m}}$ group as the point group symmetry for all PA, but we may have to adopt other symmetry point groups when taking the substituted side groups into consideration. In this case, it would not be possible to separate the $1^{1} B_{v}$ and $2^{1} A_{q}$ states. Detailed study is now in progress to clarify the mechanism of the emission process in disubstituted PA derivatives.

\section{CONCLUSIONS}

In conclusions, we studied the Raman scattering in several novel $\pi$-conjugated polymers, namely, disubstituted acetylene polymers with high PL QE, using laser excitation photon energy in the range of $1.65-3.41 \mathrm{eV}$. We found that the Raman scattering frequency dispersion is smaller in disubstituted acetylene polymers than in other acetylene polymers. If we assume the model of the short conjugation length in these acetylene polymers, we can obtain the average conjugation length. We found $\mathrm{N}$ for each polymer from $\mathrm{v}_{\mathrm{c}-\mathrm{c}}$ as following: $\mathrm{N}=7$ for PDPA- $n \mathrm{Bu}, \mathrm{N}=5$ or 6 for PHxPA and PELPA. The related energies of the $1^{1} B_{v}$ and $2^{1} A_{\vartheta}$ can be estimated from these $N$ to be; PDPA- $n B u: E\left(1^{1} B\right)=3.01 \mathrm{eV}, \mathrm{E}\left(2^{1} A_{\vartheta}\right)=2.43 \mathrm{eV}, \mathrm{PHxPA}$ and PEtPA: $\mathrm{E}\left(1^{1} B_{\jmath}\right)=3.22-3.51 \mathrm{eV}, \mathrm{E}\left(2^{1} A_{\vartheta}\right)=2.68-3.03 \mathrm{eV}$. These are in good agreement with the absorption and PL spectra, respectively, and may show that the high PL is in fact related to " $2^{1} A_{g}$ " in these polymers.

\section{ACKNOWLEDGMENTS}

We thank W. Gellerman and M. Yoshida for the help with the Raman measurements. This work was supported in Part by the DOE grant No. FG-03-96 ER 45490.

\section{REFERENCES}

1. L. Lauchlan, S. Etemad, T. -C. Chung, A. J. Heeger and A. G. MacDiarmid, "Photoexcitations in polyacetylene", Phys. Rev. B24, pp. 3701-3711, 1981.

2. K. Yoshino, S. Hayashi, Y. Inuishi, K. Hattori, and Y. Watanabe, "Photoluminescence of cis- and trans-polyacetylene, Solid State Commun. 46, pp. 583-585, 1983.

3. T. Masuda, T. Hamano, K. Tsuchihara, and T. Higashimura, "Synthesis and Characterization of 
Poly[[o-(trimethylsilyl)phenyl]acetylene]", Macromolecules 23, pp. 1374-1380, 1990.

4. H. Shirakawa, T. Masuda, and K. Takeda, "The Chemistry of Triple-Bonded Functional Groups", ed. S. Patai (John Wiley \& Sons, New York) Chap. 17, pp. 945, 1994.

5. M. Hirohata, K. Tada, R. Hidayat, T. Masuda, and K. Yoshino, "Effect of alkyl and aromatic substituents on blue electroluminescence in polyacetylene derivatives", Jpn. J. Appl. Phys. 36, L302-L305, 1997.

6. M. Ozaki, M. Liess, R. E. Benner, Z. V. Vardeny, K. Yoshino, and R. Sugimoto, “Optical studies of electronic states and coupled vibrations in substituted polyacetylene", Synth. MeL. 84, pp. 511-512, 1997.

7. M. Ozaki, R. E. Benner, Z. V. Vardeny, E. Ehrenfreund, "Dispersion of resonant Raman scattering in luminescent and non-luminescent conjugated polymers", Synth. Met. 84, pp. 489-492, 1997.

8. H. E. Schaffer, R. R. Chance, R. J. Silbey, K. Knoll, and R. R. Schrock, "Conjugation length dependence of Raman scattering in a series of linear polyenes: Implications for polyacetylene”. J. Chem. Phys. 94, pp. 4161-4170, 1991.

9. B. E. Kohler, C. Spangler, and C. Westerfield, "The $2^{1} A_{g}$ state in the linear polyene $2,4,6,8,10,12,14,16$-octadecaoctaene", J. Chem. Phys. 89, pp. 5422-5428, 1988. 